\title{
El Partido Socialista Portugués y la literatura de combate. La obra literaria de Ernesto da Silva (1868-1903)
}

\author{
The Portuguese Socialist Party and the fighting literature. The work \\ of Ernesto da Silva (1868-1903)
}

\author{
BEATRIZ PERALTA GARCÍA \\ Universidad de Oviedo \\ bperalta@uniovi.es
}

Resumen: El artículo analiza la producción literaria del Partido Socialista Portugués desde su fundación hasta la proclamación de la Primera República. Al mismo tiempo, se distingue la aportación de Ernesto da Silva, compositor tipógrafo y dramaturgo de prestigio dentro del movimiento obrero. Para ello se analiza la trayectoria del Partido Socialista como estructura partidaria de referencia de la literatura generada en su seno.

Palabras clave: Ernesto da Silva, literatura obrera, Partido Socialista Portugués, teatro socialista.

Abstract: In this paper it is analised the literary work of the Portuguese Socialist Party since it was founded until the First Republic was proclaimed.. At the same time, it is significant the contribution of Ernesto da Silva, an outstanding typographical composer and playwright of the labour movement. The purpose of this research is settle the Socialist Party as a party structure reference for the literature created in these times..

Keywords: Ernesto da Silva, working literature, Portuguese Socialist Party, Socialist theatre. 
"[...] só sabe ser operário o que é socialista!"”.

En la historia del Partido Socialista Portugués muchos son todavía los elementos a estudiar, en particular, el cúmulo de personalidades políticas cuya biografía está aún por hacer. Entre ellas destaca la figura olvidada de António Ernesto da Silva, compositor tipógrafo, socialista, poseedor de una interesante obra política y literaria hoy desconocida escrita entre 1892, cuando ingresa en las filas del Partido Socialista Portugués, y 1903, año de su prematuro fallecimiento, que marca un punto de inflexión dentro de la "literatura de combate" vinculada a esta organización partidaria. Su percurso vital acompaña la vida del Partido hasta la proclamación de la República por lo que fue testigo privilegiado de sus tensiones, escisiones y fracturas, llegando a protagonizar, incluso, una de ellas. A dar a conocer su obra recuperándola del olvido está destinado este artículo.

\section{El Partido Socialista Portugués entre 1875 y 1910}

Ernesto da Silva (1868-1903) ve nacer, a la edad de siete años, al Partido Socialista Portugués, fundado oficialmente el 10 de enero de 1875 con los "écos da proclamação da Comuna de Paris" de fondo, a raiz de los acuerdos tomados en el congreso de la Asociación Internacional de Trabajadores reunido en 1872 en La Haya, que decidió la creación de los partidos socialistas nacionales ${ }^{2}$. Las fuentes muestran que el proceso fue largo, con la organización de diversas asociaciones de carácter obrero que acabaron por confluir en la constitución de Fraternidade Operária, así como el protagonismo dado al movimiento por un intelectual de prestigio, Tarquinio Antero de Quental (1842-1891), que había formado parte de una agrupación llamada Centro Promotor das Classes Laboriosas (1852) donde convivían liberales progresistas (o "setembristas", esto es, los partidarios de la revolución de 1836 y de la Constitución de 1822), republicanos, socialistas y masones, influidos por las doctrinas de Fourier y Saint-Simon. El Centro desarrollaba una intensa actividad propagandística publicando

\footnotetext{
${ }^{1}$ Ernesto da Silva, “A sesta (Diálogo operário)”, en A Federação, 23 de septiembre de 1894.

${ }^{2}$ Nogueira, César, Resumo histórico dos congressos e conferências do Partido Socialista Português (1871-1926), Lisboa, Revista Pensamento, 1932, p. 7.
} 
periódicos, organizando conferencias y fomentando el asociacionismo con la creación de la Comissão Promotora das Associações Operárias. Bajo este modelo Antero organiza, junto a un grupo de jóvenes universitarios —Jaime Batalha Reis, Eça de Queiroz, Alberto Fuschini, José Tedeschi, Teófilo Braga y Oliveira Martins- y líderes obreros como Nobre França o José Fontana, las célebres Conferências do Casino Lisbonense a finales de mayo de 1871, que alumbrarían uno de sus textos más emblemáticos, Causas da decadência dos povos peninsulares nos últimos três séculos, donde abogaba por la unificación de la península Ibérica bajo un Estado federal y socialista. Unos días después de la disertación de Antero y mientras se celebraban las conferencias - suspendidas el 26 de junio por el gobierno conservador del duque d'Avila por "sustentar doutrinas e proposições que atacam a religião e as instituições políticas do estado" " - llegaron a la ciudad tres internacionalistas españoles, Francisco Mora, Tomás González Morago y Anselmo Lorenzo, huyendo de la persecución policial en España y con la idea de constituir en Lisboa la sección portuguesa de la Internacional con vistas a lograr la entrada de Portugal en la organización durante la celebración de la Conferencia de la Primera Internacional en Londres del 17 al 23 de septiembre de 1871. Inmediatamente entraron en contacto con el Centro Promotor y con varios de sus dirigentes más destacados, como Batalha Reis, Antero y Fontana. Las reuniones entre españoles y portugueses se celebraron bajo un secretismo nocturno y romántico, a bordo de un bote "cacilheiro", en el Tajo, lugar sugerido por el mismo Fontana, sabedor de que una polícia recelosa los vigilaba. Acompañado por Batalha Reis, Antero pagó al barquero para que les permitiese remar solos y esperó en el lugar convenido donde Fontana aguardaba con "os internacionalistas". "E durante horas, [relata Jaime Batalha Reis] nessa noite e nas seguintes, sobre o Tejo, enquanto eu remava, o Antero discutia com os emissarios socialistas a revolução operária que já lavrava em Europa". El mismo Francisco Mora se hacía eco del episodio en una carta enviada a Valencia, donde escribió:

\footnotetext{
"Depois de vencer as dificuldades que se opunham ao nosso intuito, conseguimos fundar en Lisboa uma secção da A (refere-se à Aliança), a que, bem depressa, se há-de seguir a constituição da Federação local lisbonense da Associação Internacional dos Trabalhadores. Isto é: o germe da nova ideia na região portuguesa; e esperamos que dê excelentes resultados, pois as notícias que temos do Porto, Coimbra, Évora e outros pontos são magnificas"s.
}

Sin embargo, las condiciones no resultaron favorables y Antero, temiendo la reacción de las autoridades, se limitó a fundar una "asociación de resistencia" y un periódico, O Pensamento Social (23 de febrero de 1872), para difundir el ideal socialista. Paralelamente, aparecieron varias organizaciones en Lisboa vinculadas, estas sí, a la Internacional: una, fundada por Nobre

\footnotetext{
${ }^{3}$ Quental, Antero, Causas da decadência dos povos peninsulares nos últimos três séculos, Lisboa, Tinta-da-China, 2011, p. 103.

${ }^{4}$ Nogueira, César, Notas para a história do socialismo em Portugal (1871-1910), Lisboa, Portugalia Editora, 1964 , p. 23 .

${ }_{5}^{5}$ Ibídem, p. 28.
} 
França; otra, con participación de González Morago, vinculada al conde de Peniche, se reunía en el Palácio do Fiúza, en la parroquia de Alcântara, donde el sacerdote republicano João Bonança (1836-1924)6 publicaba O Trabalho, "que estes operários, quase todos compravam"; y una tercera, liderada por Fontana, denominada Associação Protectora do Trabalho Nacional. Esta, junto a un grupo que se reunía en la sala de la Sociedade dos Artistas Lisbonenses, dará lugar a la Associação Fraternidade Operária (1871), inspirada en las trade unions británicas. A finales de diciembre se celebraron las reuniones para la aprobación de sus estatutos y el 19 de enero de 1872 se constituían oficialmente. El 30 de septiembre, tras la organización de la sección portuense de la Fraternidade, Antero escribió otro de sus opúsculos más conocidos, $O$ que é a Internacional?, aunque sin acabar de adherirse formalmente a este organismo. Las razones, según Nobre França, tenían que ver con el razonamiento que Antero hacía de la evolución de los acontecimientos históricos, pues entendía que era necesario realizar una revolución política antes de llegar a una transformación económica. Para Nobre França el planteamiento debía ser justo al contrario, según le escribió a Engels en una misiva, en la que observaba que "o que foi um «resultado» querem que seja uma «causa»". Otras asociaciones se reunían en Alfama y Chelas y en localidades como Almada, Poço do Bispo y Marvila, todas ellas cercanas a Lisboa. En un primer intento de unión la asociación liderada por Nobre França se asoció con las de Alfama y Chelas, adoptando como marco normativo los estatutos de Fraternidade Operária.

Pero a pesar de las reticencias de Antero y su grupo el día 10 de marzo de 1872 la sección portuguesa del socialismo formalizaba su adhesión a la Internacional, poco antes de la llegada de Paul Lafargue a Lisboa, trasladado allí desde Madrid para conseguir también la asunción de los socialistas portugueses a la línea marxista. Las gestiones de Lafargue fueron existosas pues representaría a Portugal en el Congreso de La Haya y eso tuvo una importancia decisiva para la historia del movimiento obrero portugués, que a partir de ese momento abandonó las propuestas anarquistas de Bakunin. La profesora Maria Filomena Mónica explica que las razones de esta elección son desconocidas pero apunta como causas posibles la debilidad de la agrupación portuguesa, recientemente constituida, la influencia de Lafargue, el impacto del debate entorno a la Unión Ibérica - los socialistas españoles se mantendrían inicialmente fieles al ala libertaria ${ }^{9}$ - y los movimientos insurreccionales desarrollados por João Bonança, vinculado a la Associação do Trabalho Nacional, en Lisboa ${ }^{10}$.

En 1873 las agrupaciones obreras se reorganizaron en dos alas bien definidas: la sindical, dando lugar a la Associação dos Trabalhadores na Região Portuguesa, producto de la reunión de Fraternidade Operária, la Associação do Trabalho Nacional y otros grupos menores; y la

\footnotetext{
${ }^{6}$ Autor de unas Questões da actualidade (1868), de carácter federal-socialista donde defendía un comunitarismo agrario de base municipalista.

${ }^{7}$ Oliveira, César de, 13 cartas de Portugal para Engels e Marx, Lisboa, Iniciativas Editoriais, 1978, p. 21.

${ }^{8}$ Ibidem, p. 25.

${ }^{9}$ Juliá, Santos, Los socialistas en la política española, 1879-1982, Madrid, Taurus, 1996, pp. 16 y ss.

${ }^{10}$ Mónica, Maria Filomena, O movimento socialista em Portugal, Lisboa, Imprensa Nacional-Casa da Moeda, 1985 , pp. 38 y ss.
} 
política, con la fundación el 10 de enero de 1875, a propuesta de Azedo Gneco, del Partido Socialista em Portugal (PSP). Ernesto da Silva en sus análisis sobre el movimiento socialista responsabilizará a Fraternidade Operária de debilitar o, incluso, iludir a los obreros portugueses con su orientación "escolástica", esto es, marxista, "deixando entrever residir simplesmente na economia motivo a uma transformação social’. Y continúa:

\begin{abstract}
“O relativo atrazo da epocha, justificando má assimilação doutrinaria, poude no emtanto florescer até 1873, sustentando o embate de numerosas gréves, feitas sem consciencia, proprias do espirito empresssionavel do proletariado nacional que julga —á força de ignorancia- poder transformar-se o mundo d'um dia, sem cuidar das tristes desillusões que ofuturo reserva á inconsciente imprevidencia"11.
\end{abstract}

Esta dicotomía inicial será la condicionante, en buena medida, de la división de los socialistas portugueses en dos tendencias dificilmente reconciliables que perdurará, con pequeños períodos de unidad, a lo largo de las décadas siguientes y la responsable, también, de la debilidad del movimiento socialista que ni el desencanto con la proclamación de la República fue capaz de superar.

En 1878, en el II Congresso dos Socialistas Portugueses, reunido en Oporto entre los días 1 y 4 de febrero, el Conselho Central propuso la fusión de las "agrupações socialistas numa associação política e económica" ". Nace entonces el Partido dos Operários Socialistas de Portugal (POSP) de la disolución de la Associação dos Trabalhadores, que en el momento de su desaparición efectiva, en diciembre de 1879, contaba con 913 socios, y el Partido Socialista em Portugal con el objetivo de fortalecer la dimensión política de la organización, pues se pensaba que al priorizar la lucha económica el movimiento se había debilitado ${ }^{13}$. En ese mismo año celebraría su III Congresso Nacional (Lisboa, 22 a 25 de marzo), que registra la participación, por primera vez, de Luís de Figueiredo representando al Centro Operário de Lisboa. Junto a António Lúcio Fazenda, Nobre França y Celestino Aspra encarna la corriente opuesta a Gneco, priorizando la lucha económica y el papel de las asociaciones sindicales en el seno del movimiento.

Los deseos de unidad no fueron, sin embargo, duraderos. En 1880 Luís de Figueiredo consigue que el IV Congresso Nacional (Oporto, 23 a 25 de octubre) apruebe un documento suscrito por él mismo, Ermelindo António Martins, Eduardo de Carvalho e Cunha —que pasaron a formar parte del Conselho Central-, Lúcio Fazenda y Manuel José da Silva en el que se declara que

\footnotetext{
${ }^{11}$ Silva, Ernesto da, "O movimento operario II", en A Obra. Orgão dos carpinteiros civis, 18 de diciembre de 1898, p. 2.

${ }_{12}^{12}$ Nogueira, César, Resumo histórico... op. cit., pp. 16-20.

${ }^{13}$ Ibidem, p. 19.
} 
" a linha de conduta a seguir pelo partido socialista deverá ser aquela que mais rapidamente conduzir à implantação do colectivismo. Nêste intuito, o partido servir-se-á da política como meio de acção a aproveitar a representação e melhoramento do proletariado; como se poderá aproveitar da grève, da cooperativa, etc, na ordem economica"14.

Se trata de la corriente "posibilista" defendida por Benoit Malon y Paul Brousse que, años más tarde y con otra factura vendría a ser defendida, paradójicamente, por Ernesto da Silva, él mismo un admirador de Malon. A partir de 1882, tras la celebración en la Câmara Municipal de Lisboa del Congresso das Associações (10 a 18 de junio), los sindicatos de clase afirmaron su aceptación del programa socialista pero reclamaron, al mismo tiempo, su autonomía llegando la Associação de Classe dos Torneiros a sublevarse contra el partido organizando un congreso obrero $^{15}$. Hacia 1890 las diferencias eran ya notables, aunque la fecha marca, sin embargo, un hito en la historia del movimiento obrero en Portugal con la aparición masiva de nuevos sindicatos. César Nogueira, uno de los primeros historiadores del movimiento socialista en Portugal, fija en la aprobación en septiembre de 1887 del "Regulamento para a cobrança da contribuição industrial", por el gobierno liberal progresista de José Luciano de Castro y su ministro de Hacienda, Mariano Cirilo de Carvalho, la denominada "Lei das licenças para trabalhar", este momento de inflexión organizativa a nivel sindical. El reglamento obligaba a obtener un permiso para "exercer uma indústria, profissão, arte ou oficio" y al pago del impuesto correspondiente por el tiempo de su duración, que se fijaba en tres, seis, nueve o doce meses. Al repercutir en los bolsillos de los dueños de las fábricas y jefes de obra el coste del permiso de contratación de los empleados la norma provocó las airadas protestas de los propios patronos, tanto o más que las de los obreros, por lo que el gobierno se vio obligado a introducir modificaciones que aliviasen los elementos más sangrantes, como la exención de la contribución industrial hasta determinados umbrales salariales y para algunos productos o profesiones, la eliminación de la pena de prisión en caso de infracción de la norma, o la posibilidad del pago del impuesto en prestaciones mensuales ${ }^{16}$.

Dentro del movimiento socialista fue la Associação dos Trabalhadores, situada en la lisboeta Calçada de S. Francisco, 15, cuyos miembros recibían el nombre de "franciscanos", la que más se significó en contra de la ley. En el sur (Lisboa), la dirigían João Ramos Lourenço, Agostinho José da Silva, Manuel Luís de Figueiredo y Manuel Martins Correia. En el norte (Oporto), Eduardo de Carvalho e Cunha y Francisco Viterbo de Campos ${ }^{17}$. El movimiento

\footnotetext{
${ }^{14}$ Ibídem, p. 25; también, del mismo autor, Nogueira, César, Notas para a história ... op. cit., pp. 114-115; Mónica, Maria Filomena y Maria Goretti Matias, Manuel Luís de Figueiredo. Um socialista ignorado, Lisboa, Instituto de Ciências Sociais da Universidade de Lisboa, 1986, pp. 7 y ss.

${ }^{15}$ Mónica, Maria Filomena, O movimento socialista... op. cit., p. 60.

16 "Regulamento para a cobrança da contribuição industrial» y "Alterações à lei das licenças para trabalhar", apud Fonseca, Carlos da, História do movimento operário e das ideias socialistas em Portugal. IV. Greves e agitações operárias (1 ${ }^{a}$ parte), Lisboa, Publicações Europa-América, 1982, pp. 179-182 y 187.

${ }^{17}$ Nogueira, César, Resumo histórico... op. cit., pp. 159-162.
} 
obrero, un tanto adormecido hasta la fecha, pareció revivir a raiz de las protestas y las huelgas provocadas por la aprobación de la ley y llevó a la eclosión de las asociaciones de clase que el Estado hubo de reconocer a partir de 1891, tras la celebración de un congreso en la Câmara Municipal de Lisboa el 4 de enero, que reunió a noventa delegados de cincuenta asociaciones y núcleos obreros de todo el país ${ }^{18}$.

Este fortalecimiento del ala sindical acentuó las tensiones dentro de los socialistas portugueses, que para 1892 estaban claramente escindidos en dos facciones: la llamada posibilista, dirigida por Luís de Figueiredo, y la marxista o revolucionaria de Azedo Gneco. La división se consumó durante la celebración del Congresso Nacional das Associações de Classe el 24 de marzo de 1892 en Oporto, con cincuenta y nueve delegados que representaban a treinta y cuatro asociaciones y agrupaciones obreras. Los delegados de la región sur abandonaron las reuniones descontentos con los preparativos para la celebración de la manifestación del $1^{\circ}$ de mayo, la superioridad atribuida a una de las organizaciones portuenses frente a otras dos, y la supuesta debilidad del movimiento asociacionista en Lisboa. Diferencias de procedimiento que, sin embargo, ocultaban opciones estratégicas distintas pues el congreso acabó por aceptar la constitución de la Federação das Associações de Classe en Lisboa que, junto a su homóloga de Oporto, se alinearon con el ala marxista de Azedo $\mathrm{Gneco}^{19}$. Tras el congreso las dos facciones del movimiento socialista se consolidaron, especialmente en Lisboa y en Oporto. En la capital, los posibilistas o "franciscanos" de Luís de Figueiredo se reunían en la sede de la Associação dos Trabalhadores y publicaban $O$ Protesto Operário, y en Oporto, el semanario O Trabalhador. La disidencia marxista, por su parte, se organizó en el Centro Operário Socialista del Pátio do Salema, lo que dio origen a la denominación de "salemistas", y comenzaron a publicar O Revolucionário ( $1^{\mathrm{a}}$ serie). En Oporto, donde fundaron el Centro Operário de Propaganda Socialista, su máximo animador era Francisco Viterbo de Campos y su órgano de expresión $O$ Eco Socialista. En estas dos últimas publicaciones, alineado con el ala marxista, inicia Ernesto da Silva su andadura dentro de la organización socialista y sus colaboraciones periodísticas, que ya nunca abandonaría ${ }^{20}$. Además, formó parte del grupo que organizó la publicación $A$ Federação, el semanario de la Federação das Associações de Classe (1893) cuyo redactor principal es Azedo Gneco, y en él permanecerá hasta abril de 1896.

A partir de 1895 las divergencias entre el ala sindicalista y el ala política dentro del Partido dos Operários Socialistas, acentuadas a lo largo de 1893 y 1894, culminan en una fractura que se prolongará durante diecisiete años, solo soldada en 1907 cuando en vísperas de la proclamación de la Primera República (1910-1926) se produzca la ansiada unidad. La facción marxista de Azedo Gneco, denominada Partido Socialista Portugués, constituyó un directorio

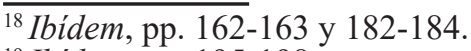

${ }^{19}$ Ibídem, pp. 195-198.

${ }^{20}$ Una aproximación a él es posible en Ventura, António, "Ernesto da Silva e o socialismo", en Leal, Ernesto Castro (coord.), Republicanismo, socialismo, democracia, Lisboa, Centro de História da Faculdade de Letras da Universidade de Lisboa, 2010, pp. 169-182.
} 
integrado por él mismo, Ernesto da Silva y Teodoro Ribeiro que dirigió los destinos del partido hasta 1896. Para presentarlo oficialmente y aprobar su programa se convocó un congreso en Tomar, ciudad próxima a Lisboa, con motivo de las fiestas del centenario de Gualdim Pais ${ }^{21}$ entre los días 14 a 16 de octubre de 1895 celebrado bajo el nombre de II ${ }^{a}$ Conferencia Socialista. En 1896 se eligió un nuevo Conselho Central integrado por Eudoxio César Azedo Gneco, Teodoro Carlos Ribeiro, Ernesto da Silva, José Maria de Oliveira e Silva, José do Carmo, Carlos Rio de Carvalho y Domingos Henriques Nunes da Silva ${ }^{22}$. Pasan entonces a existir dos agrupaciones socialistas distintas, con dos sedes diferentes y dos agrupaciones sindicales asociadas: el Partido dos Operários Socialistas, de tendencia posibilista, dirigido por Manuel Luís de Figueiredo, los "franciscanos", apoyado por la Liga das Associações Operárias; y el Partido Socialista Portugués, marxista, revolucionario o democrático, vinculado a Azedo Gneco, los "salemistas", al que se adscribe la Federação das Associações de Classe. Para César Nogueira la corriente posibilista contaba con los elementos de mayor "valor intelectual" mientras que la revolucionaria disponía de los más "activos" ${ }^{23}$. Aunque la primera parecía tener ligeramente más implantación, las agrupaciones más débiles tendían a preferir a la segunda ${ }^{24}$.

A pesar de esta fractura en el seno del movimiento Luís de Figueiredo no duda en calificar el período 1895-1897 de "fecundo" por la vitalidad de la acción propagandística y la difusión doctrinaria $^{25}$. La unidad, no obstante, estaba lejos de conseguirse debido, en parte, a las tensiones dentro del Partido Socialista Portugués, que empezaron a ser visibles rápidamente, a propósito de la orientación que Azedo Gneco imprimió a la nueva formación. Unos días antes de la celebración del congreso de Tomar, ya Ernesto da Silva se mostraba muy crítico con la acción revolucionaria y defendía la necesidad de que el Partido Socialista participase en política:

“Luctando politicamente, o povo operario recebe a precisa educação á
justa comprehensão dos seus direitos de cidadão, e progressivamente vae
activando o desmoronamento fatal do privilgio capitalista, levado ao maximo
da transigencia pela força popular, sem ter resolvido o problema social
do desequilibrio economico. [...] O socialismo não quer a revolução pela
revolução, mas pelo que contém de transformador nas relações individuaes e
de progressivo na constituição das sociedades. Não basta correr o sangue, é
preciso primeiro illuminar a consciencia popular immersa nas densas trevas
da ignorancia e desconhecimento das origens do mal que a todos faz soffrer"

Aunque según un anónimo cronista —que así se expresa en 1906-Azedo Gneco intentó apaciguar los ánimos dimitiendo del Conselho Federal, la medida no fue suficiente. Fue en este

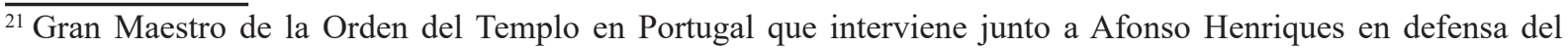
territorio frente a los moros.

${ }^{22}$ Nogueira, César, Notas para a história... op. cit., pp. 215-217; ídem, Resumo histórico... op. cit., pp. 36-43.

${ }^{23}$ Nogueira, César, Notas para a história... op. cit., p. 210.

${ }^{24}$ Mónica, Maria Filomena, O movimento socialista... op. cit., p. 65.

${ }^{25}$ Nogueira, César, Notas para a história... op. cit., p. 237.

${ }^{26}$ Silva, Ernesto da, “A Questão Social. IV", en O Proletario de Coimbra, 5 de octubre de 1895, p. 1.
} 
momento cuando "Ernesto da Silva pôz-se á frente d'um socialismo novo, que nunca explicou, nem pessoa alguma entendeu". "A situação [continúa] tornou-se tensa em demasia, sem que ninguem pudesse explicar o motivo. O tal socialismo novo não era nada, ou, pelo menos, nunca foi dito o que era". La crisis estalló en el verano de 1896, tras el regreso de Azedo Gneco del Congreso Internacional Socialista (Londres, 26 a 31 de julio), al que había asistido como delegado, y la huelga de los empleados del gas. Cuando volvió, explica nuestro cronista, el "socialismo novo" había progresado, aunque sí se llegó a una conclusión: " $O$ socialismo novo é o Ernesto da Silva" ${ }^{27}$.

Las acusaciones de ser "um elemento dissolvente" o lo que es lo mismo, de connivencia con los anarquistas, empezaron en 1897 aunque Azedo Gneco solo las hará públicas un año más tarde, en 1898, en una serie de artículos publicados en el periódico A Federação entre el 12 y el 26 de junio ${ }^{28}$. Ernesto da Silva, por su parte, que había alcanzado una notoriedad importante no solo como propagandista y conferencista en los centros y asociaciones obreras a los que solía acudir con regularidad como invitado sino sobre todo tras el arrollador éxito de su obra más emblemática, $O$ capital, representada a finales de 1895, entendía el anarquismo "como ultima manifestação do progresso da ideia que ora defendo", esto es, una etapa en el proceso de liberación definitiva del Hombre, lo que le valió la denominación de "socialista libertario" 29. El 6 de junio de 1897 A Federação publicaba la carta que el día 2 había enviado al Centro Socialista de Lisboa anunciando su "retirada da vida activa do movimento operario, forçado pela absoluta falta de saúde e desgostos soffridos" ${ }^{30}$. Paralelamente, comenzó su aproximación con el movimiento republicano pues entendía que el deber de los socialistas era trabajar para la proclamación de la República, que no concebía como un fin en sí mismo, sino un medio para la construcción de la sociedad socialista ${ }^{31}$. De ahí su colaboración en periódicos como $A$ Vanguarda, dirigida en estos años por Magalhães Lima, primero, y después en $O$ Mundo, de França Borges.

Esta crisis, aquí apenas esbozada, llevó a una nueva escisión dentro del socialismo portugués con la creación de Aliança Republicana-Socialista, encabezada por Ernesto da Silva y Teodoro Ribeiro y un conjunto de seguidores agrupados en torno al periódico A Obra, el órgano de los carpinteros civiles. El campo de batalla fue la cooperativa A Lusitana, que enfrentaba dos modelos de gestión: el "systema da empreitada industrial", esto es, la concesión global de la obra, con capital extranjero; y el que defendía la intervención de la asociación de clase y la libertad individual del trabajo. Para Ernesto da Silva, "a 1. ${ }^{a}$ corrente é puro «possibilismo» de

\footnotetext{
27 "Questão necessaria”, en O Primeiro de Maio. Folha socialista, 2 de septiembre de 1906, p. 4.

${ }^{28}$ Vid., por ejemplo, "Liga das Artes Graphicas", en A Federação, 13 de junio de 1897, p. 2; Gneco, Azedo, "Provase a traição", en A Federação, 12 de junio de 1898, p. 2; 19 de junio de 1898, p. 1; y 26 de junio de 1898 , p. 2.

29 "Setúbal", en A Federação, 17 de marzo de 1897, pp. 1-2; "Ernesto socialista", en O Mundo, 27 de abril de 1903. Para un análisis del pensamiento de Ernesto da Silva vid. Ventura, António, Anarquistas, republicanos y socialistas em Portugal. As convergências possíveis (1892-1910), Lisboa, Edições Cosmos, 2000, pp. 108-116.

30 "Centro socialista de Lisboa", en A Federação, 6 de junio de 1897, p. 3.

${ }^{31}$ Vid., por ejemplo, su artículo titulado "A defesa da Republica", en O Mundo, 14 de octubre de 1900, p. 1.
} 
jogo pessoal, sem preoccupações de maior, emquanto a $2{ }^{a}{ }^{a}$ é socialismo puro que não se prende com dogmas e só tem por «eschola» a verdade inteira e completa" ${ }^{2}$.

Estas explicaciones de Ernesto da Silva, realizadas en 1899 en una "Carta Aberta. (Aos camaradas do norte)" cuestionan, o al menos, matizan, afirmaciones posteriores entorno a la actitud mantenida por la dirección del Partido en Oporto ante Aliança Republicana-Socialista. El anónimo cronista de 1906 la responsabilizó de acusar a Azedo Gnecco de ser "afecto al republicanismo" y de "transigencia con la democracia burguesa". Según él, los socialistas de Lisboa se mantuvieron fieles a su línea partidaria y no participaron en un acuerdo para concurrir a las elecciones junto al Partido Republicano, por lo que fueron atacados por los "nuevos socialistas", que reclamaron una "concentração democratica" que no era sino "a morte do partido socialista". Los "novos socialistas" pasaron todos a ser "republicanos socialistas" César Nogueira, en su análisis sobre el período, también responsabilizó a los republicanos de estar detrás de esta nueva escisión con el objetivo de impedir el avance del socialismo en Portugal ${ }^{34}$.

La nueva agrupación, por lo demás, apenas tuvo recorrido aunque sí es cierto que los socialistas, que hasta ese momento se habían negado a presentarse a las elecciones, comenzaron a considerar la posibilidad de participar en política, asumiendo de este modo las recomendaciones del Congreso Internacional celebrado en París en 1900. Así, con motivo de las elecciones municipales de ese mismo año y después de algunas tensiones internas, los socialistas entablaron negociaciones con el Partido Republicano para la elaboración de una lista de "concentração democrática" en Lisboa con la inclusión de "um nome socialista", el de Manuel José da Silva, junto a republicanos de renombre, como Alexandre Braga, José Estêvão de Vasconcelos o Manuel Brito Camacho. Obtuvo 3191 votos y se consideró un fracaso ${ }^{35}$.

Hasta la muerte de Ernesto da Silva en 1903 el Partido Socialista Portugués siguió reorganizándose y expandiéndose, tanto a nivel interno como internacional, adhiriéndose en 1904 al Consejo Internacional Socialista, para lo que designó a Azedo Gneco como su representante. Según asevera César Nogueira la adhesión no prosperó al no satisfacerse las cuotas establecidas, aunque vuelve a intentarlo en $1906^{36}$. Además, y por sus conexiones con los socialistas españoles, resulta de particular interés la celebración de tres congresos obreros internacionales galaico-portugueses, el primero de ellos en Vigo (17-19 de enero de 1901) y el segundo en Viana do Castelo (15-20 de abril de 1902), aunque aquí solo tomaría parte la sección obrera del norte de Portugal. El congreso de Vigo decidió la creación de dos comisiones internacionales compuestas por cinco miembros cada una, con sedes en Vigo y Viana, y el

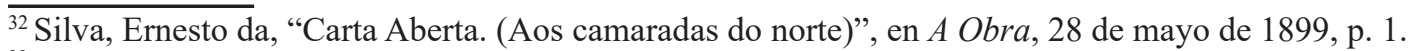

33 "Questão necessaria..." op. cit.

${ }^{34}$ Nogueira, César, Notas para a história... op. cit., p. 239.

${ }^{35}$ Ibídem, p. 257.

${ }^{36}$ Por resolución de la $1^{a}$ Conferencia Extraordinária Nacional Socialista (Tomar, 30 de junio de 1906). Vid. Nogueira, César, Notas para a história... op. cit., pp. 275 y 284; e ídem, Resumo histórico... op. cit., pp. 48-49.
} 
mandato de celebrar congresos entre ambos países. Durante la celebración del segundo se avanzó en la integración entre los socialistas españoles y portugueses con la creación de una Unión Obrera Internacional Galaico-Portuguesa, y se aprobó su respectivo reglamento. Además, las comisiones se integraron dentro de un organigrama mayor al establecerse una Comisión Internacional Galaico-Portuguesa.

Aún habría de celebrarse un tercer congreso, esta vez en Braga (20-27 de abril de 1903). Las delegaciones intentaron avanzar en los trabajos, discutiendo cómo evitar las huelgas y su consiguiente rebaja de salarios; el trabajo de mujeres y niños en las fábricas, y la necesidad de reformar el reglamento interno de la Unión Obrera Internacional Galaico-Portuguesa. Entre los acuerdos adoptados estuvo el de impulsar la celebración de sesiones de propaganda en España y Portugal, mientras que en el plano organizativo interno se decidió la celebración del siguiente congreso, en septiembre de 1904 en Pontevedra, mientras que los posteriores se reunirían cada dos años. No obstante, César Nogueira, a quien seguimos en estas notas, no registra la concretización efectiva de estos acuerdos que achaca, una vez más, a la perniciosa influencia de la propaganda republicana ${ }^{37}$.

El 1 de noviembre de 1903, con motivo de las elecciones municipales, el Partido Socialista decide finalmente votar la lista republicana. Desde Setúbal, O Trabalho, de Luís de Figueiredo lo anunciaba con estas palabras: "Os socialistas da feição Gneco resolveram na capital votar com a lista republicana, oferecendo aos republicanos todo o seu auxilio" ${ }^{38}$. Sin embargo, decidió no acudir a las parlamentarias de 26 de junio de 1904 aunque la iniciativa de un grupo de socialistas de Oporto de presentar una lista a las elecciones, que no fue respaldada por la Junta Federal do Norte do Partido Socialista, demuestra las disensiones en torno a este asunto en el interior de la organización.

A partir de 1905 el Partido Socialista Portugués ve decaer su influencia dentro de las masas obreras. César Nogueira lo achaca a la apuesta del Partido Republicano por la lucha política frente al Partido Socialista, que siempre se decantó por la vertiente económica. Un "erro de táctica" acordado en el Congresso Socialista Federal do Sul (2 de abril) cuya Junta — de la que formaba parte Azedo Gneco- dio a la luz un manifiesto afirmando que el Partido Socialista "não estorvará a acção do Partido Republicano [...] sem deixar de ver nele um partido contrário, que apenas visa a democratização do regime capitalista" ${ }^{39}$. No fue esta situación, sin embargo, la que llevaría a reconstituir la perdida unidad sino la fidelidad de los socialistas portugueses a las decisiones tomadas en las reuniones internacionales. En 1907 el Congreso Internacional de Amsterdam decretó la existencia de un solo Partido Socialista como

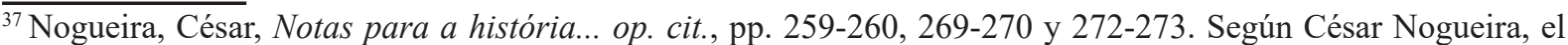
primero reunió a 27 delegados de 82 agrupaciones, diez de ellos portugueses representando a 39 asociaciones, y 27 gallegos de 43 asociaciones, mientras que en el tercero participaron 88 asociaciones, 30 gallegas y 58 portuguesas, con 27 delegados, siete gallegos y 14 portugueses.

${ }^{38}$ O Trabalho, 1903, apud ibídem, p. 274.

${ }^{39}$ Ibidem, pp. 280-283.
} 
estrategia de lucha contra los partidos burgueses, y en consonancia con ello, procedieron a la constitución de una única agrupación partidaria. La ocasión la propició la celebración del $1^{\circ}$ de mayo, donde José Fernandes Alves instó a la superación de antiguas rencillas. El día 5 de mayo, una comisión nombrada el 2 de abril acordaba la celebración de una Conferência Socialista da Região do Sul (Lisboa, 1 de junio a 30 de diciembre) que habría de proceder a la revisión del programa y de su reglamento, y a la acción y táctica que se debería seguir a partir de ese momento. Un año más tarde sería el turno de la Junta Federal do Norte (Oporto, 25 de octubre a 13 de diciembre). En ambos casos, las juntas regionales resultaron integradas por personas de todas las "tendências e facções socialistas" aunque sin formalizar la elección de un Conselho Geral que aglutinase a ambas tendencias y dirigiese los destinos del Partido. Este solo se constituirá oficialmente el día 23 de abril de $1910^{40}$.

Pero a pesar de este esfuerzo el Partido Socialista Portugués continuó siendo una agrupación de escasa fuerza en el panorama nacional. El mismo César Nogueira registra su limitada importancia en vísperas de la proclamación de la República. En 1908 las asociaciones de Lisboa y Oporto decidieron participar en las elecciones parlamentarias, a pesar de que la Junta Regional do Sul había decidido abstenerse, y en noviembre los socialistas de Lisboa acudieron a las municipales y a las de juntas de parroquia, donde lograron que la lista socialista fuese la más votada en Oeiras. Este año Eduardo de Abreu y Azedo Gneco se desplazaron a Madrid invitados por los socialistas españoles con motivo de la inauguración de su Casa del Pueblo. El primero acudió en representación de la Federação Tipográfica, de la Associação dos Compositores Tipográficos de Lisboa y de la Liga das Artes Gráficas do Porto; Azedo Gneco, por su parte, representó al Partido Socialista Portugués, y a la Federação Operária de Lisboa, y fue uno de los oradores que tomó la palabra durante el acto ${ }^{41}$. Un año más tarde, el partido hubo de enfrentar una nueva disidencia en el Congresso Operário Nacional de 1909, cuando en la sección de Lisboa un sector se posicionó abiertamente a favor de apoyar la proclamación de la República y solo después abordar la organización de la sociedad socialista. Esta nueva fractura llevó a la constitución de una nueva agrupación tras la celebración del Congresso de Organização Sindical que dio origen a União Operária Nacional y después a la Confederação Geral do Trabalho, de inspiración anarco-sindicalista.

La Primera República se proclamó el día 10 de octubre de 1910 tras el éxito de un golpe de Estado organizado por el Partido Republicano Portugués. El Partido Socialista Portugués permaneció al margen del movimiento revolucionario.

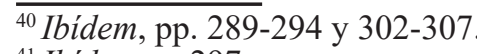

${ }^{41}$ Ibídem, p. 297.
} 
2. Literatura y propaganda en el Partido Socialista Portugués (1875-1910)

Los socialistas se demoraron en la utilización de la literatura como instrumento de difusión doctrinal, que no encuentra carta de naturaleza hasta la realización del $\mathrm{II}^{\circ}$ Congresso Socialista da Região Sul en 1914, tras la proclamación de la República. Las dificultades para la configuración de una organización cohesionada y bien implantada dentro del movimiento obrero así como la adopción de la política como medio más adecuado para la construcción de la sociedad socialista, retardaron esta adopción. Así pues el conjunto de las manifestaciones literarias socialistas entre los años 1875 hasta 1910, cuando se proclama la República son, en buena medida, aún desconocidas, especialmente la narrativa. La lírica está representada, sobre todo, por la obra ingente, inédita y dispersa por la prensa obrera, de Joaquim dos Anjos aunque otros nombres podemos unir al suyo, como el de la republicana y feminista Angelina Vidal, autora de una vasta producción poética y dramática de denuncia social aún por estudiar, o Francisco António da Assumpção, cuyas composiciones aparecieron en la prensa partidaria, como A Luz do Operário (Oporto), A Batalha Socialista (Lisboa) (bajo el pseudónimo de "Vergueiro") y $O$ Combate (Lisboa), por anotar solo algunas figuras señeras ${ }^{22}$. Los pocos estudios que poseemos sobre el tema demuestran que se trata de una poesía de autor que distingue entre autores clásicos consagrados, portugueses o extranjeros, y militantes socialistas. Entre estos últimos se diferencian dos modelos de colaboración entre los que mantienen con los periódicos una relación coyuntural dando lugar a la publicación de poemas de forma esporádica, y los intelectuales obreros, que suelen disponer de una sección fija ${ }^{43}$.

Poesía y teatro son, a priori, los géneros más cultivados dentro del movimiento socialista. El segundo, por su especial capacidad para combinar espectáculo y enseñanza y por su dificultad técnica, es cultivado por una élite intelectual y es también del que poseemos más referencias, sobre todo para los años de la República (1910-1926) ${ }^{44}$. Para el período anterior, que media entre la fundación del Partido Socialista Portugués y 1910, las noticias son más escasas. Tenemos conocimiento de que, pocos años antes de la fundación efectiva del PSP y la crisis de 1895, un

\footnotetext{
${ }^{42}$ Peralta García, Beatriz, "Poesía y política en la prensa obrera. Las «Carapuças d'O Socialista»", en Marcos de Dios, Ángel (coord.), Relaciones lingüisticas y literarias entre Portugal y España desde inicios del siglo XIX hasta la actualidad, Salamanca, Universidad de Salamanca, 2007, pp. 269-279; Santos, Licínio Manuel Moreira dos, Cultura e Lazer Operários em Gaia, entre o final da Monarquia e o início da República (1893-1914), tesina de máster, Universidad de Oporto, 2014, p. 47 y ss., y anexo 4, p. 48, donde el autor del trabajo transcribe el poema de Francisco António da Assunção titulado "Caridade".

${ }^{43}$ Peralta García, Beatriz, "Poesía y política..." op. cit.

${ }^{44}$ Vid., por ejemplo, Peralta García, Beatriz, La cultura obrera en Portugal. Teatro y socialismo durante la Primera República (1910-1926), Mérida, Junta de Extremadura, 2009; Peralta García, Beatriz, "Autores y obras de teatro socialistas en Portugal durante la Primera República, 1910-1926”, en Álvarez, Amparo et al. (coords.), El siglo XX: balance y perspectiva. Actas del V Congreso Nacional de la Asociación de Historia Contemporánea, Valencia, Fundación Cañada Blanch, 2000, pp. 213-218; Peralta García, Beatriz, "Literatura y movimiento obrero en Portugal: la cultura política del socialismo en su teatro", en Espacio. Tiempo y Forma. Serie Historia contemporánea, 23 (2011), pp. 37-54.
} 
joven Ladislau Batalha había hecho sus pinitos en el teatro con la elaboración de una comedia de situación titulada Consequências de um sim (1873), según los cánones estéticos de la época y sin más pretensiones que el entretenimiento de los espectadores. Con un contenido más político podemos citar un drama de propaganda republicana hoy perdido, O Rouget de Lisle —sobre la vida de Claude Rouget de Lisle, el autor de La Marsellesa (1792) —, de Dionisio Sampaio, fallecido prematuramente, aunque sin poder aportar una fecha de composición ${ }^{45}$. Contemporánea en el tiempo parece ser la producción dramática de Luís de Figueiredo, situada hacia la década de los años 70 e inicios de los 80, durante los años que dirigió el Partido dos Operários Socialistas de Portugal, integrada por varias obras: A ultima favorita, Dramas da realeza, Fidalgos e populares, O canalha y Os jesuitas (h. 1881). De estos cinco textos solo fueron representados los dos últimos y Os jesuitas. Drama original portuguez, em três actos, además, publicado en 1883, donde su autor critica la acción de los miembros de la Compañía de Jesús en la sociedad ${ }^{46}$. En 1888 un joven José Fontana da Silveira publica Honra e trabalho. Drama historico e educativo em 1 acto, basado en la vida del arquitecto francés Miguel Sedaine, que estudia gracias a la ayuda de un benefactor ${ }^{47}$. En 1898 documentamos la existencia de A Tecelã, un drama en tres actos "dedicado á classe textil" de António da Silva Restolho48. Esto es, en veinte años de historia del socialismo en Portugal apenas tenemos conocimiento de ocho obras teatrales que todavía en estos años oscilan entre la denuncia social y la defensa de un sistema republicano. En general, carecen de contenido ideológico por lo que no podemos denominarlas “socialistas” en sentido estricto. De ahí que el grupo de Azedo Gneco, al fundar el Grupo Dramático Socialista en 1893, recurriese a obras del teatro social para construir su repertorio dramático, textos muy conocidos de autores como Eduardo Pedro Baptista Machado, como Gaspar, o serralheiro (1877) ${ }^{49}$, Pedro Carlos de Alcântara Chaves, João, o corta-mar, o Eduardo Baptista Diniz, Veterano da Liberdade. Así nace la idea de dotar a la recién creada agrupación dramática de un repertorio acorde con el pensamiento socialista. José Martins Santareno se autoatribuye la iniciativa, que traslada a Ernesto da Silva, autor de algunos textos literarios publicados en A Federação. Durante los primeros meses de 1895 este compondrá la

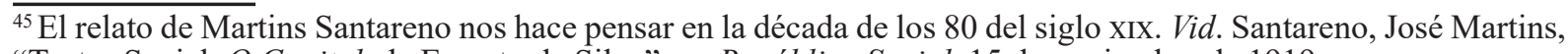
"Teatro Social. O Capital, de Ernesto da Silva", en República Social, 15 de noviembre de 1919.

${ }^{46}$ Figueiredo, Manuel Luís, Os jesuítas. Drama original portuguez, em 3 actos, Lisboa, Agencia Teatral, Biblioteca Progresso Teatral, 1883. Sobre la obra vid. Peralta García, Beatriz, La cultura obrera en Portugal... op. cit., pp. 154 y 157.

${ }^{47}$ Silveira, José Fontana da, "Honra e Trabalho. Drama histórico e educativo em 1 acto, baseado na vida de Miguel Sedaine, eminente architecto francez", en Encyclopedia das Famílias: Revista de Instrução e Recreio, 362-366 (1888), pp.

48 “A Tecelã”, en O Tecido. Órgão da União das Classes Textis em Portugal, 2 de enero de 1898, p. 4. El periódico lo anuncia como un "novo drama" del autor que debía ser representado en uno de los teatros de Lisboa.

${ }^{49}$ Se trata de una de las obras más conocidas del teatro social de finales del siglo XIX en Portugal. Además de su representación en estos años, fue recuperada por otros grupos teatrales pasando a formar parte de su repertorio en 1913 y 1919, cuando podemos documentar su representación. Vid. Peralta García, Beatriz, La cultura obrera en Portugal... op. cit., pp. 187 y 241-286, reproducción del texto que respeta el original portugués.
} 
primera obra de carácter ideológico del teatro socialista, $O$ capital, cuya complejidad excedía las posibilidades dramáticas del teatro de aficionados y hubo de ser representada, con un importante éxito de público, el 8 de noviembre de 1895 por los profesionales del Teatro do Príncipe Real ${ }^{50}$. El éxito llevaría a su edición por la tipografía del Instituto Geral das Artes Graphicas (el sindicato tipógrafo) en 1896.

La obra suposo un acicate para el autor pero también para otros intelectuales obreros, como el caso del antes citado António da Silva Restolho, de manera que podemos situar con ella el inicio de una dramaturgia socialista propiamente dicha. Su éxito vino a corroborar uno de los puntos del programa del escindido y recién nacido Partido Socialista Portugués, la facción de Azedo Gneco, aprobado en la II ${ }^{\mathrm{a}}$ Conferencia Nacional Socialista, reunida en Tomar hacía apenas quince días: el de la necesidad de proceder a una amplia labor de difusión del ideal socialista. Las propuestas iban desde la organización de actos dentro de las asociaciones, como conferencias y fiestas, hasta un conjunto de elementos de carácter "menor" pero de extraordinaria capacidad simbólica, con especial relevancia para las obras de arte, sin olvidar, por supuesto, la prensa como canal de difusión. De ahí que solo un año más tarde, en 1897, Ladislau Batalha llevase a escena el drama A miséria en el Coliseu dos Recreios con motivo de la celebración del $1^{\circ}$ de mayo ${ }^{51}$. En 1903 Angelina Vidal escribe Nobreza de alma, ambientada en el mundo laboral, mientras que Um sonho socialista (1905), de Francisco Miguel Penha, permanecerá inédita hasta 1920, cuando fue publicada por $O$ Combatente (Faro) ${ }^{52}$. Concentra, en sí misma, los cuatro ejes temáticos del teatro establecidos para el teatro socialista portugués de la Primera República: la denuncia de la sociedad capitalista, el diseño de la sociedad socialista, la exposición de los valores de clase y la lucha por la hegemonía dentro del movimiento obrero frente a los anarquistas ${ }^{53}$. Relata esta las condiciones laborales de los obreros en las fábricas, marcadas por la inseguridad, la presión sexual sobre las mujeres, las tensiones con los anarquistas, y la organización feliz del nuevo orden socialista ${ }^{54}$. Significativamente, entre el texto de Ladislau Batalha y el de Angelina Vidal podemos fijar la cronología de la obra de Ernesto da Silva. Así, para el periodo de 1895 a 1910 tenemos conocimiento documentado de la composición de una docena de textos dramáticos, siete de ellos de nuestro autor, una nómina que su prematuro fallecimiento vino a interrumpir.

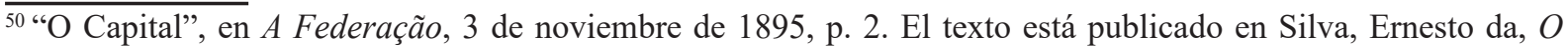
Capital. Drama original em 4 actos, Lisboa, Typographia do Instituto Geral das Artes Graphicas, 1896.

51 "Congresso operario. 4" sessão ordinária", en $A$ Vanguarda, 20 de abril de 1897, p. 2; "Centro socialista occidental", en A Vanguarda, 23 de abril, p. 3.

${ }^{52}$ Vid. Peralta García, Beatriz, La cultura obrera en Portugal... op. cit., pp. 49-59.

${ }^{53}$ Ibídem, pp. 89-90.

54 "Um sonho socialista", en $O$ Combatente, 8 de febrero a 1 de agosto de 1920.
} 
3. La obra de Ernesto da Silva (1893-1903)

\subsection{La obra dramática (textos teatrales y textos dramáticos)}

La producción literaria de Ernesto da Silva se sitúa, por lo tanto, en el punto de inflexión que supuso el desarrollo de los acontecimientos de 1895, y está aún por identificar en su totalidad, documentar y fijar, aunque los datos que poseemos nos permiten afirmar que estaría compuesta por una obra dramática integrada por textos teatrales y textos dramáticos; y una obra narrativa de relatos breves, estos últimos significativamente olvidados tras el arrollador éxito de $O$ capital. Textos dramáticos y relatos breves alcanzan la treintena, publicados en $A$ Federação dentro de la sección dedicada al "Folhetim" entre 1893 y 1896, antes de abandonar la agrupación de Azedo Gneco. En 1901, además, realizó una breve colaboración en la recién creada Revista Nova.

Bajo el epígrafe de "textos teatrales" consideraremos todos aquellos textos escritos para ser representados en los teatros. Hay que situar, en el momento de su muerte, los primeros intentos por inventariar la obra dramática de Ernesto da Silva como reconocimiento a una intensa labor de difusión del pensamiento socialista, muy conocida porque fue representada o publicada en la prensa partidaria en vida del autor, convirtiéndolo en una figura carismática no solo dentro del movimiento obrero, donde era ya un líder reconocido, también como dramaturgo, especialmente con la última, en la que la crítica ve una evolución técnica sustancial. Al día siguiente de su fallecimiento el periódico $O$ Mundo publicó el siguiente elenco: $O$ capital. Drama original em 4 actos (1896); A vitima (1896), cuya representación fue rechazada por el teatro de D. Maria; Os que trabalham. Drama em 4 actos, también representado en el Teatro do Príncipe Real el 23 de marzo de 1897; Nova aurora. Apropósito dramático em 1 acto e 3 quadros, representado em 1 de maio de 1900 no Príncipe Real. (Genero symbolico); Despertar. Alegoria social em um acto, aparecida en A Obra; Vencidos (o Os Vencidos da vida). Drama em 4 actos (1902), y Em ruinas. Peça em 3 actos (1903), publicada unos días antes de su muerte y también rechazada por otro teatro, esta vez el de D. Amelia, pero cuya representación estaba prevista en Brasil por la compañía de Sousa Bastos. El periódico informa además de que había presentado una obra en un acto a un concurso organizado por el Ateneu Comercial do Porto, del que por ser reciente todavía no se conocían los resultados ${ }^{55}$. Puede tratarse de Os honestos, anunciada "em preparação" dentro de las obras atribuidas a Ernesto da Silva en la edición de Em ruinas.

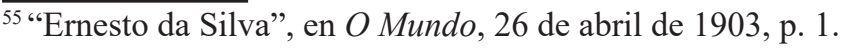


En junio, el columnista teatral de $A$ Vanguarda analizó estas obras en relación con la vida de su autor, motivo por el cual las dividió como representativas de dos grandes etapas: la popular y la artística. A la primera pertenecen, según Fernando Reis, O capital, Os que trabalham, As victimas [sic.] y Nova aurora, todas ellas llevadas a escena entre 1895 y 1900 . El crítico destaca de ellas el apego de Ernesto da Silva a los problemas de los obreros y su intento por trasladarlos a los escenarios como una forma de denuncia social. La segunda estaría integrada por apenas dos obras, Os vencidos y Em ruinas, donde el autor habría evolucionado privilegiando los elementos literarios. Esto es, a decir de Fernando Reis los primeros textos adolecerían de un exceso de contenido ideológico aproximándolos al "teatro de tesis", mientras que los segundos se acercarían más al denominado "drama social”. El mismo Ernesto da Silva parece apreciar esta evolución en su percepción de los modelos genológicos teatrales como elementos configurativos de la dramaturgia obrera socialista, según defendió en una conferencia dictada en el Ateneu Comercial de Lisboa en diciembre de 1901 dentro de un ciclo organizado por los fundadores del Teatro Livre titulada Teatro livre e arte social ${ }^{56}$. Fue también el primero -y único- en teorizar las características que debería tener un teatro socialista. Lo hizo en el texto citado y en algunos artículos de crítica teatral publicados en la prensa. Para Ernesto da Silva el teatro debía tener como objetivo denunciar la desigualdad de la sociedad capitalista, difundir el pesamiento socialista y favorecer la moralidad de las costumbres entre los espectadores. Por ello criticaba el teatro de consumo y la exhibición de obras de escaso gusto propias de la comedia, la opereta y la revista. Frente a ello, apostaba por obras de contenido social y moralizante tomando como referencia el drama de actualidad y la comedia de situación o, incluso, el drama histórico. Además, el nuevo teatro debía ser producto de la iniciativa de una élite intelectual frente al Estado. De ahí su crítica a éxitos teatrales como A rosa engeitada, de D. Joao da Câmara ${ }^{57}$ y, sobre todo, las representaciones infantiles de teatro, donde los pequeños actores llevaban a escena obras teatrales para adultos ${ }^{58}$. Desde el punto de vista de la difusión doctrinal sus dramas, por el contrario, se integrarían dentro de dos de los ejes temáticos antes enunciados: la denuncia de la sociedad capitalista y el diseño de la sociedad socialista ${ }^{59}$. Así, según esta clasificación, podríamos adscribir O capital, Os que trabalham, A victima y Vencidos (o Os vencidos da vida), al primero, mientras que Nova aurora, Despertar y Em ruinas pertenecerían al segundo.

Paralelamente, Ernesto da Silva dio a la luz un conjunto de "textos dramáticos" que, aunque susceptibles de ser llevados a los escenarios, han permanecido como ejercicios literarios pues, al margen de presentar una estructura dialogada, carecen de la habitual división en actos,

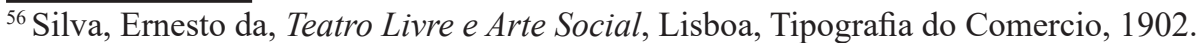

${ }^{57}$ Silva, Ernesto da, "A «Rosa Engeitada»", en O Mundo, 29 de enero de 1901, p. 2.

${ }^{58}$ Silva, Ernesto da, "Associação Promotora das Festas Infantis. Na cooperativa «A Liberdade»", en O Mundo, 29 de julio de 1901; y el artículo "A traço negro... (Typos e factos). Opiniões", en O Mundo, 5 de agosto de 1901, p. 1, donde critica con severidad, en polémica con Anna de Castro Osorio y Costa Carneiro, la situación de los niños en las compañías infantiles de teatro, como las representaciones del teatro do Infante: "Acaso não esbarramos ahi a cada passo com a Gata assanhada, a Osga, o Lareco, o Rei da fome, ladrões e meretrizes de 10 a 13 annos passeando impavidos ares de criminosos feitos e gestos obscenos de prostitutas impuberes trescalando a poder?". ${ }_{59}$ Peralta García, Beatriz, La cultura obrera en Portugal... op. cit., pp. 90-108.
} 
escenas o cuadros, de elenco de personajes y de dirección escénica. Ni el periódico O Mundo ni el crítico Fernando Reis parecen conocer su existencia, ahogados por el paso del tiempo datan de entre 1893 y 1896-, el anonimato de su autor — aparecieron bajo el pseudónimo de Ruy- y el brillo escénico de obras posteriores. Se publicaron en el periódico A Federação, el semanario surgido como órgano de la Federação das Associações de Classe bajo la dirección de Azedo Gneco. Él mismo, junto a un equipo en el que se encontraba Ernesto da Silva, es el redactor de la nueva publicación que incorpora, como otras, una sección titulada "Folhetim". Se trata de una sección fija, generalmente pero no únicamente, literaria, a la que el crítico António Pedro Lopes de Mendonça (1826-1865), vinculado con el movimiento socialista —es el fundador, junto a Vieira da Silva y Sousa Brandão de Eco dos operarios, uno de los primeros periódicos dedicados a los obreros en Portugal一, otorgó un estilo propio en los periódicos de la burguesía que sirvió como modelo a autores posteriores, como los conocidos folletinistas Júlio César Machado, Pinheiro Chagas o Ramalho Ortigão $0^{60}$. Los periódicos obreros, entre ellos los socialistas, no tardaron en adoptarlo como uno más entre los instrumentos de difusión doctrinaria donde publicaron textos de divulgación teórica, programáticos y literarios.

Como en el caso de la mayoría de los textos teatrales los textos dramáticos pertenecen a la primera fase descrita por Fernando Reis, caracterizada por su propensión hacia el "teatro de tesis", por lo que podemos adscribirlos a los siguientes ejes temáticos: 1. la denuncia de la sociedad capitalista: Á saída da fábrica (Diálogo operário), De volta á fábrica (Diálogo operário), Á porta da venda (Diálogo operário) y A sopa (Dialogo); 2. el diseño de la sociedad socialista: 1871, No gabinete (Dialogo burguez), A sesta (Dialogo operario) y Do alto das ruínas (Diálogo operário); 3. el compromiso ético y moral: Á ceia (Á redacção da "Voz do Operario") (Dialogo burguez) y A pátria (Dialogos); y 4. la lucha por la hegemonía dentro del movimiento obrero: Á saída do atelier. Entre costureiras y No tanque (Entre lavadeiras). En todos ellos el autor nos presenta una estructura dicotómica absoluta de la sociedad, bien reconocible para el público asistente, con un mensaje claro y sin fisuras a favor del ideal socialista.

\section{2 Los relatos breves}

Constituyen el conjunto narrativo más desconocido de la obra literaria de Ernesto da Silva y, como los textos dramáticos, vieron la luz intercalados con ellos en A Federação, firmados también bajo el pseudónimo de Ruy. Nuevamente responden a la misma tipología que observamos para caracterizar los textos teatrales y los textos dramáticos aunque, a diferencia de ellos, aquí únicamente podemos señalar dos ejes temáticos: la denuncia de la sociedad capitalista: Um reprobo, A pneumonia, Perdida ..., O aborto, Luz e sombra (Phantasia), A fábrica, O batesorna, $O$ voto, $O$ suicida, No cemitério y A criminosa; y el diseño de la sociedad socialista:

\footnotetext{
${ }^{60}$ Vid. Ribeiro, Maria Manuela Tavares, Teorias e Teses Literárias de António Pedro Lopes de Mendonça, Coimbra, Centro de História da Sociedade e da Cultura da Universidade de Coimbra, 1994.
} 
Um encontro. (Phantasia), Na avenida, O pesadello y $O$ tio Cholera. A diferencia de los textos teatrales y dramáticos, donde Ernesto da Silva amplía el abanico temático, en las narraciones breves el mensaje ideológico aparece de forma más intensa por lo que, desde el punto de vista narratológico, podríamos adscribirlas a la "narración de tesis".

En 1901 aceptó colaborar con Revista Nova (5 de abril de 1901 a 31 de enero de 1902), una publicación dirigida por Ilídio Analide da Costa como editor literario, de la que se publicaron apenas ocho números. Además de autores portugueses conocidos en el panorama intelectual de la época, encontramos publicaciones de Juan Ramón Jiménez, Jacinto Benavente, Francisco Villaespesa, Salvador González Anaya, Rubén Darío, Enrique Gómez Carrillo, Miguel de Unamuno y Viriato Díaz Pérez. En ella publicó O Intruso, donde aborda un tema que lo obsesionaba, el aborto, desde una perspectiva crítica a las teorías neo-malthusianas ${ }^{61}$.

$\overline{{ }^{61} \text { Vid. Revista Nova }}, 20$ de mayo de 1901,pp. 78-82. Sobre los autores españoles o del mundo hispánico, consúltense los ocho números. 